\title{
Uterine adenosarcomas: A tertiary cancer center experience
}

\author{
Ilker Kahramanoglu, Fuat Demirkiran, Hasan Turan, Tugan Bese, Macit Arvas \\ Division of Gynecologic Oncology, Department of Obstetrics and Gynecology, \\ Cerrahpasa School of Medicine, Istanbul University, Istanbul, Turkey
}

\section{Introduction}

Mullerian adenosarcoma is a very rare malignancy composed of benign epithelial and malignant stromal components. Uterine adenosarcomas (UAs) account for 5.5\% of all uterine sarcomas. Even though these tumors are considered as less agressive tumors than uterine carcinosarcomas, recurrence rate may reach up to $40 \%$ (Arend R. et al., 2010).

Due to its rarity, there are limited data on the optimal therapy and prognostic factors.

In this study, we investigated the clinicopathological features, treatment and recurrence patterns of the patients with UA treated at our institution.

\section{Patients and Methods}

A retrospective analysis of all patients with UA from 1 January 1998 to 1 May 2018 was performed. Demographic, clinicopathological and treatment data were abstracted from the patients' medical records.

\section{Results}

A total of 8 women were identified and included into study. Median follow-up was 59 months. The median age at the time of diagnosis was 62 years (31-69 years). Four patients had UA with sarcomatous overgrowth. Seven patients underwent complete surgical staging including total hysterectomy with bilateral salpingo-oophorectomy, pelvic-paraaortic lymphadenectomy and omentectomy. Only one patient underwent total hysterectomy with bilateral salpingooophorectomy only. Patients were staged as follows according to FIGO 2009 staging system: 2 patients had stage 1A, 2 patients had stage $1 \mathrm{C}, 2$ patients had stage $2 \mathrm{~B}$ and 2 patients had stage $3 \mathrm{~B}$ diseases. Only one patient had a residual disease $(>1 \mathrm{~cm})$ after surgery. None of the patients had a lymph node involvement. Three patients received adjuvant chemotherapy (two of them had sarcomatous overgrowth). Five of 8 patients had tumor recurrence. Recurrence sites were as pelvis in 1 patient, upper abdomen and pelvis in 3 patients, and abdomen and lung in 1 patient. Three of these 5 had sarcomatous overgrowth. The other patient with sarcomatous overgrowth died 3 months after surgery. Median overall survival was 47 months within a median follow up of 83 months.

\begin{tabular}{|c|c|c|c|c|c|c|c|}
\hline Patient No. & Age (years) & Final pathology & Surgery & FIGO Stage & $\begin{array}{l}\text { Adjuvant } \\
\text { treatment }\end{array}$ & Recurrence & $\begin{array}{l}\text { OS } \\
\text { (months) }\end{array}$ \\
\hline 1 & 67 & UA & CSS & IA & - & - & 89 \\
\hline 2 & 59 & UA & $\mathrm{TAH}+\mathrm{BSO}$ & IA & - & - & 118 \\
\hline 3 & 31 & $\mathrm{UA}+\mathrm{SO}$ & CSS & IIB & $\mathrm{CT}$ & $+($ pelvis $)$ & 39 \\
\hline 4 & 61 & $\mathrm{UA}+\mathrm{SO}$ & CSS & IIIB & $\mathrm{CT}$ & $\begin{array}{l}+ \text { (pelvis }+ \text { upper } \\
\text { abdomen })\end{array}$ & 14 \\
\hline 5 & 57 & UA & CSS & IC & $\mathrm{CT}$ & - & 91 \\
\hline 6 & 63 & UA & CSS & IIIB & - & $+($ abdomen + lung $)$ & 9 \\
\hline 7 & 63 & $\mathrm{UA}+\mathrm{SO}$ & CSS & IIB & - & - & 55 \\
\hline 8 & 69 & $\mathrm{UA}+\mathrm{SO}$ & CSS & IC & - & - & 3 \\
\hline
\end{tabular}

\section{Abbreviations:}

SO: Sarcomatous overgrowth. CSS: Complete surgical staging.

CT: Chemotherapy. OS: Overall survival.

\section{Conclusion}

Herein, we present our 20-year experience of UA. Sarcomatous overgrowth seems to be associated with an increased risk of recurrence and a decreased overall survival. A future metaanalysis may provide an information about the role of adjuvant therapy. 